\title{
Using unmanned aerial vehicle photogrammetry for digital geological surveys: case study of Selmun promontory, northern of Malta
}

\author{
Emanuele Colica ${ }^{1}$ (D) Sebastiano D'Amico $^{1} \cdot$ Roberto lannucci $^{2} \cdot$ Salvatore Martino ${ }^{2} \cdot$ Adam Gauci $^{1}$. \\ Luciano Galone ${ }^{1} \cdot$ Pauline Galea ${ }^{1} \cdot$ Antonella Paciello $^{3}$
}

Received: 17 November 2020 / Accepted: 30 July 2021 / Published online: 14 August 2021

(c) The Author(s) 2021

\begin{abstract}
In recent years, we have been witnessing the widespread use of low-cost, increasingly high-performance Unmanned Aerial Vehicles, or UAVs, equipped with a large number of sensors capable of extracting detailed information on several scales and in an immediate manner. This study was motivated by the need to perform a geological survey in an area with difficult physical access, and to compare the results with those from conventional surveys. Here we used a Multirotor UAV equipped with a high definition RGB camera and the digital photogrammetry technique to reconstruct a three-dimensional model of the Selmun promontory, located in the northern part of the island of Malta (central Mediterranean Sea). In this area, the evident cliff retreat is linked to landslide processes involving the outcropping geological succession, characterized by the over position of stiff limestones on ductile clays. Such an instability process consists of a lateral spreading associated with toppling and fall of different-size rock blocks. Starting from the 3D model obtained from the UAV-photogrammetry, a digital geological-structural survey was performed in which we identified the spatial geometry of the fractures that characterize the area of the Selmun promontory by measuring strike, dip and dip direction of the fractures with semi-automatic digital tools. Furthermore, we were able to measure the size and volume of singularized rock masses as well as cracks, and their sizes were mapped in a GIS environment that contains a large number of digital structural measures. It is the first application of this type for the Maltese islands and the results obtained with this innovative digital methodology were then compared with those of the traditional field survey of the same area acquired during a previous campaign. This study demonstrated how the innovation of digital geological surveying lies in the possibility of mapping areas and geological features not detectable with traditional methods, mainly due to the high risk associated with the stability of the cliff or, more generally, the inaccessibility of some sites, therefore allowing the user to operate in safety and to detect in detail the most remote rocky outcrops.
\end{abstract}

Keywords UAV $\cdot$ Photogrammetry $\cdot$ Geophysics $\cdot$ Remote sensing $\cdot$ Image processing $\cdot$ Geological survey

\section{Introduction}

Photogrammetry is the technique to build measurable three-dimensional models using a large number of photographs acquired through a single (or multiple) standard camera for close-range targets. We can refer to digital

Emanuele Colica

emanuele.colica@um.edu.mt

1 Department of Geosciences, University of Malta, Msida, Malta

2 Department of Earth Sciences and Research Center for Geological Risks CERI, University of Rome "Sapienza", Rome, Italy

3 ENEA C.R. Casaccia, Rome, Italy photogrammetry as Structure from Motion (SfM), which is based on Computer Vision (CV) algorithms that extract the significant points from individual photos, deduces the photographic parameters and matches the recognizable points on multiple photos, detecting the coordinates in the space of the points themselves (Westoby et al. 2012). The SfM only concerns the first part of the image processing methodology (image matching and sparse reconstruction), while in the second phase, which is called Multi-view Stereo Reconstruction (MVS), the low-density point cloud is thickened by increasing the number of points (dense reconstruction) (Wenzel et al. 2013). In aerial digital photogrammetry, the camera is generally installed on Unmanned Aerial Vehicles (UAVs), aeroplanes, or satellites ( $\mathrm{Li}$ et al. 2003). The recent advancements both in 
terms of technology and software developments have given a boost to such applications in several fields (e.g., Colica et al. 2017; D'Amico et al. 2017; Galea et al. 2018; Remondino et al. 2011; Casella et al. 2017; Menegoni et al. 2019; Westoby et al. 2012). Primarily, photogrammetry has been used in geosciences for the reconstruction of landforms; for example, digital elevation models (Fonstad et al. 2013), topographic and surface models (Heng et al. 2010), and geomorphological investigations (Chandler 1999; Lane 2000; Grosse et al. 2012; Menegoni et al. 2019; Wu et al. 2018).

In the last few years, the use of photographic data acquired by UAV has grown significantly. This is not surprising, since UAVs equipped with a photographic sensor are relatively low-cost, especially when compared to Lidar equipment and/or aircraft photogrammetry. UAV investigations coupled with a Differential Global Navigation Satellite System (DGNSS) and a powerful computer can produce an output with an average accuracy better than $2 \mathrm{~cm}$ (Gonçalves et al. 2015) and they allow rapid investigations on large areas.

UAV-photogrammetry also has some limitations such as: (i) accessibility to the areas in which to place the markers to be measured with the DGNSS; (ii) visibility, as photography records everything visible from the camera lens in the visible and near infrared spectrum; (iii) weather conditions, as it is not possible to fly the drone in strong winds or thunderstorms.

Engineering geologists generally utilize expertise that requires knowledge in soil and rock mechanics, groundwater, and surface water hydrology. This expertise can be certainly complemented by photogrammetry and remote sensing techniques which are relatively low-cost and allow the collection of a large amount of valuable data in a small amount of time.

Digital photogrammetry, if combined with geological and geotechnical data, can improve the characterization and understanding of landslide mechanisms, which affect, for example, coastal areas (Fazio et al. 2019), urban areas (Laribi et al. 2015) and quarries (Francioni et al. 2014), and therefore help to define mitigation solutions. In this work, we have experimented with UAV-photogrammetry to investigate whether it could be accurate enough to replace and/or implement current in-situ engineering-geological surveys. In particular, we used an alternative approach that combines photogrammetric models to perform three-dimensional fracture trace and conventional two-dimensional fracture trace mapping in a semi-automatic way.

The traditional engineering-geological rock mass characterization (ISRM 1978), with the stereographic projection of the spatial geometry of the main structures, is often laborious because data are collected manually and sometimes one finds oneself working in dangerous environments. Moreover, the completeness of the acquired data often depends on the time spent in the survey and on the accessibility to the outcrops.

In this study, results from the digital photogrammetry approach are discussed and compared with findings from a traditional engineering-geological survey conducted in the Selmun promontory area by Iannucci et al. $(2017,2018)$. In the near future, thanks to the improvement of both technology and processing techniques, the application of UAV-photogrammetry will enhance geological surveying in terms of noticeably reducing data acquisition times, while increasing data quality and completeness.

\section{Geological and geomorphological setting of the study area}

The Maltese archipelago is situated in the Central Mediterranean and it is composed of three main islands (Malta, Gozo, and Comino). It is located at about $300 \mathrm{~km}$ north of the African coast and about $100 \mathrm{~km}$ south of Sicily, in the Sicily channel, which is characterized generally by sea depths of not more than $200 \mathrm{~m}$. The islands are formed of a sequence of five main geological marine sedimentary formations consisting of a sequence of limestones, marls and clays ranging from Oligocene to the Pleistocene in age (Fig. 1A, B) (Hyde 1955; Pedley et al. 1976, 1978, 2011; Scerri 2019). The oldest outcropping unit in the islands is the Lower Coralline Limestone (LCL, Oligocene), which consist of biomicrites, coralline and coarse bioclastic sediments with a maximum thickness of $140 \mathrm{~m}$. Overlying this unit is the Globigerina Limestone (GL, Aquitanian-Serravallian), consisting of biomicrite wackestones and marls with a thickness which can locally exceed $200 \mathrm{~m}$. The Blue Clay (BC, Serravallian) covers the GL and is made of grey-green clays with thickness up to $65 \mathrm{~m}$. The Greensand is a glauconitic limestone $1 \mathrm{~m}$ thick which is only locally present over the BC (Greensand Formation, not reported in the map of Fig. 1). The Upper Coralline Limestone (UCL, Late Tortonian-Early Messinian) is the youngest lithological unit and is made of coral-algal patch reef.

Tectonically, the archipelago forms part of an intensely faulted platform stretching to eastern Sicily, which also represents an important benchmark separating the western and eastern Mediterranean basin (Pedley 2011). In such a context, the islands of Malta can be divided in three main structural regions (Pedley et al. 1976, 1978; Scerri 2019): the Malta Horst, the North Malta Graben and, in the island of Gozo, the Gozo Horst (Fig. 1A).

The Malta Horst and the North Malta Graben are separated by the WSW-trending Victoria Lines Fault (also known as Great Fault), a 14-km-long escarpment in the central part of Malta which represents the most prominent morphotectonic lineament. While to the south of this 

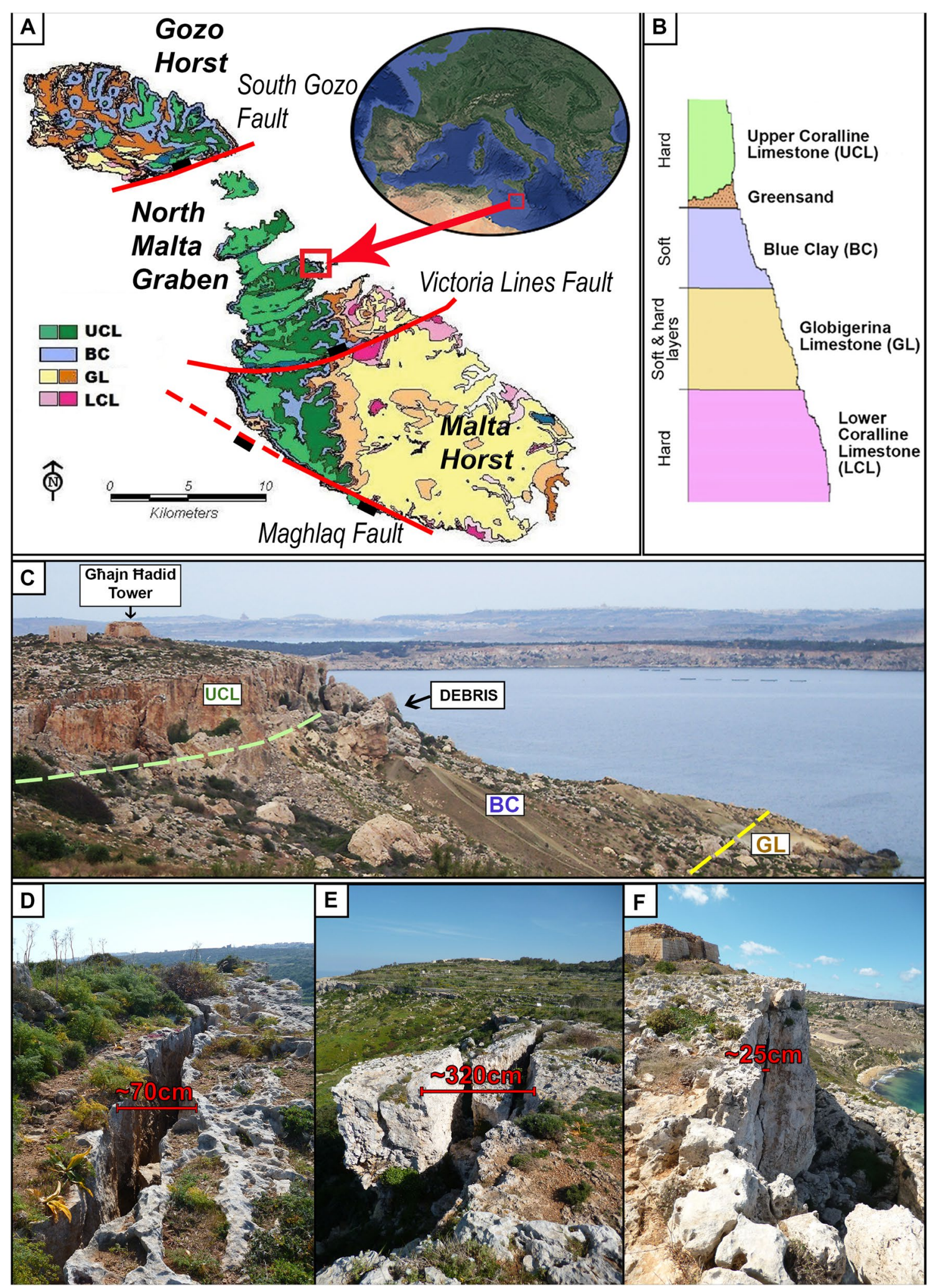

Fig. 1 A The position of the Maltese islands in the Mediterranean Sea and the location of the Selmun promontory (red square) on the geological map showing the main structural regions of the Maltese islands (modified from Oil Exploration Directorate 1993); B the sedi- mentary sequence in the Maltese archipelago; $\mathbf{C}$ photograph showing the Upper Coralline Limestone cliff, the Upper Coralline-Blue Clay and Blue Clay-Globigerina geological contacts and the UCL debris covering the BC slope; D-F images of Selmun fractures and their size 
fault the landscape is relatively flat and the outcrops are dominated by the deeper lithological units, in the northern part the structural setting is characterized by a distinctive sequence of ridge-trough morphology where the entire sedimentary sequence is outcropping. This morphology is controlled by an ENE-trending horst and graben structural style which also has a strong influence on coastal landforms. Grabens form valleys which end in bays and coves, while horsts form plateaus ending on lowland coasts or in cliffs, where the different geomechanical and hydrogeological properties of the hard limestones (UCL) overlying the clays (BC) favour the occurrence of a series of geomorphological processes. Particularly impressive are the lateral spreading phenomena, which may evolve into block sliding, rock falls and topples (Devoto et al. 2012, 2013, Mantovani et al. 2013).

This paper investigates the Selmun area which is located along the north-eastern coast of Malta where the geological succession is characterized by the over position of the stiff UCL on the soft BC. The stratigraphic succession of the Selmun promontory (Iannucci et al. 2017, 2018) consists of about $20-30 \mathrm{~m}$ of the UCL and about $50 \mathrm{~m}$ of the BC overlying the GL formation (Fig. 1C) with slightly NE-dipping strata $\left(<5^{\circ}\right)$. On the gentle slope the observed debris is mainly composed of detached UCL clasts with diverse sizes ranging from centimetre-scale clasts up to metre-size blocks which are embedded in weathered BC and residual material of limestone dissolution. The largest blocks are generally distributed in the region close to the UCL and deposits can reach several meters of thickness. The Selmun promontory can be considered as a coastal slope in general not directly affected by sea erosion, the instability being mainly controlled by gravitational processes (Martino and Mazzanti 2014). The overlying UCL limestone on the $\mathrm{BC}$ formation leads to a lateral spreading phenomenon (Goudie 2004; Panzera et al. 2012; Galea et al. 2014) which shapes a plateau of stiff rock bordered by jointed unstable cliffs, favouring the detachment of rock blocks and boulders mainly controlled by gravityinduced instability mechanisms (Fig. 1C). This process is accelerated along the coast by weathering effects and

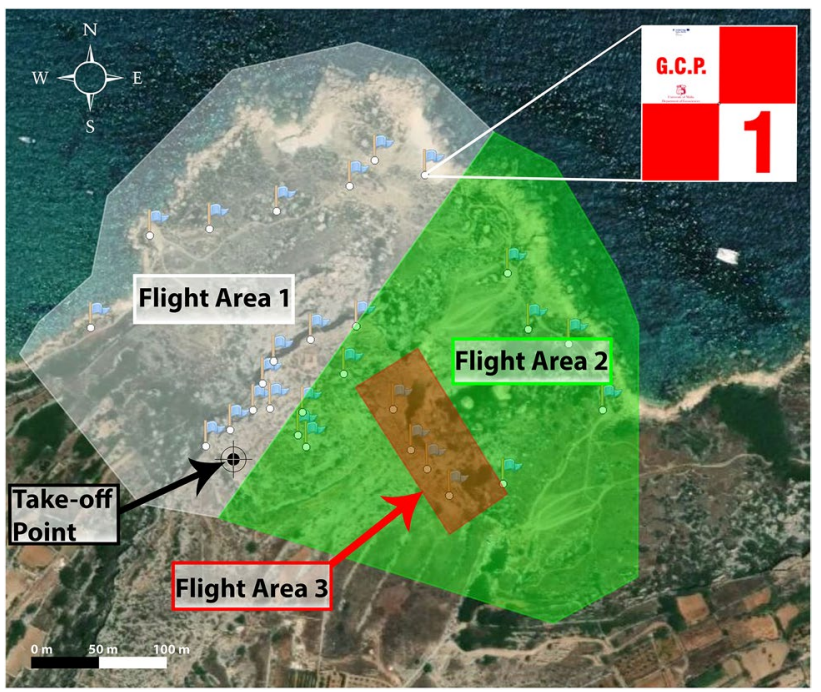

Fig. 2 Satellite image (Retrieved from https://planet.openstreetmap. org) of the Selmun promontory showing areas of the two flight plans in autonomous mode (flight 1 white area and flight 2 green area) and area 3 (in red) detected in manual flight mode $15 \mathrm{~m}$ from the target surface. The take-off point is indicated by a black crosshair and the locations of the Ground Control Points (detailed in the upper right corner) are represented by the blue flags

marine processes. This landslide process can be defined as a complex phenomenon (e.g.,Varnes 1978; Hutchinson 1988). As shown in the Figs. 1D-F, in the Selmun area, fractures in the topmost part of the plateau range from a few to tens of centimetres wide, depending on the stage of their evolution.

\section{Data collection, processing and digital geological survey method}

\section{Mission planning and image acquisition}

Photogrammetry data were collected using a UAV Phantom 4 Pro equipped with autonomous flight modes, terrain follow mode, obstacle avoidance sensors in five directions and 30 min flight time. This UAV has a new 3-axis stabilization system for an integrated professional camera with a 1"

Table 1 Summary of some fundamental parameters defined in the planning phase of the three flights aimed at the photogrammetric survey

\begin{tabular}{|c|c|c|c|c|c|c|}
\hline & $\begin{array}{l}\text { Flight height in } \\
\text { meters from take-off } \\
\text { point }\end{array}$ & $\begin{array}{l}\text { Distance in meters } \\
\text { between the camera } \\
\text { and the target }\end{array}$ & $\begin{array}{l}\text { Number } \\
\text { of images } \\
\text { taken }\end{array}$ & $\begin{array}{l}\text { Area covered per } \\
\text { scene in square } \\
\text { meters }\end{array}$ & $\begin{array}{l}\text { Images } \\
\text { resolution in } \\
\text { pixels }\end{array}$ & Main images overlap \\
\hline Automatic flight 1 & 30 & $30-100$ & 670 & $65,603.5$ & $5472 \times 3648$ & $\begin{array}{l}90 \% \text { forward and } 70 \% \\
\text { side }\end{array}$ \\
\hline Automatic flight 2 & 30 & $30-100$ & 689 & $66,971.5$ & $5472 \times 3648$ & $\begin{array}{l}90 \% \text { forward and } 70 \% \\
\text { side }\end{array}$ \\
\hline Manual flight 3 & $5-30$ & 15 & 318 & 6705.7 & $5472 \times 3648$ & $\begin{array}{l}\text { About } 90 \% \text { forward and } \\
90 \% \text { side }\end{array}$ \\
\hline
\end{tabular}




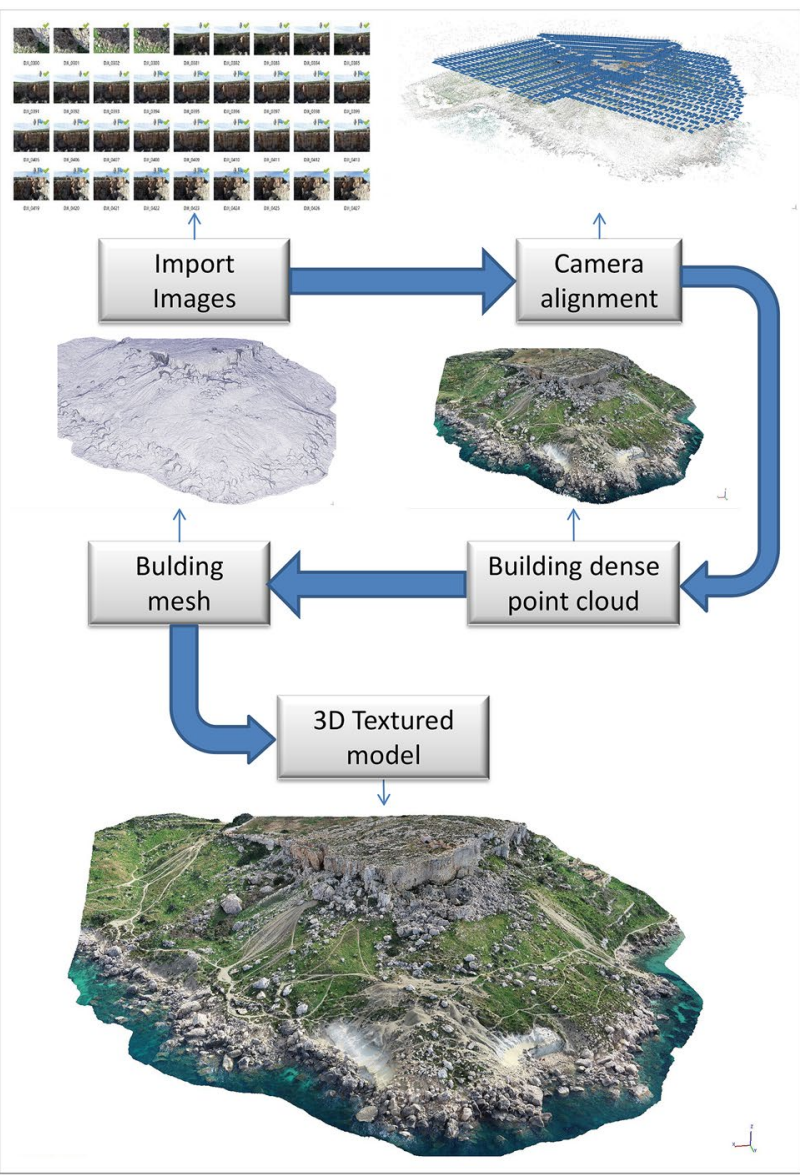

Fig. 3 Photogrammetric workflow using Agisoft Metashape software (Agisoft 2020)

Exmor R CMOS image sensor (El Gamal 2005) and resolution of 20 Megapixels.

The first phase of the fieldwork was that of the survey planning which consists of the choice of flight area, flight altitude, camera settings, positioning of the markers on the ground, and topographic measurements to support the aerialphotogrammetric survey.

The final resolution of the model depends upon the overall quality of the acquired images, while the metric accuracy depends on the positioning of the Ground Control Points (GCPs). For this reason, we have carefully designed the GCPs with high contrast pattern shapes (Fig. 2) that have allowed us to precisely locate the central points seen from the photos.

In the planning phase, it is very important to define the Ground Sample Distance (GSD) which represents the distance between the centres of two consecutive pixels expressed in territorial units (Leachtenauer 2001). The GSD depends on the geometric characteristics of the camera (sensor size and focal length used) as well as the height of flight. For autonomous flight planning, the free app Pix4D Capture (Pix4Dcapture 2018) was used and, considering the extension of the promontory, it was decided to divide the mission into two flights with a height of $30 \mathrm{~m}$ above the take-off point on the plateau (Fig. 2).

The recommended overlap values for aerial photogrammetry are at least $80 \%$ forward overlap and at least $70 \%$ for side overlap (Agisoft 2020). In our survey, to obtain high accuracy, the images were taken from a nadir-looking direction with a $90 \%$ forward overlap and $70 \%$ side overlap.

The GSD has been automatically calculated by the app because it contains in its database all the technical data related to the camera of the UAV. At $30 \mathrm{~m}$ of distance, this resulted in an estimated GSD of $0.87 \mathrm{~cm}$ per pixel. A third flight was also carried out in manual mode on the area already covered by the first flight but in this case, we acquired images with more detail on the cliff and on the large block of rock located southeast of the study area (Fig. 2) obtaining an estimated GSD of $0.44 \mathrm{~cm}$ per pixel. This was possible using the proximity sensors of the Phantom 4Pro that allowed us to maintain a constant distance of $15 \mathrm{~m}$ from the framed subject and the images were acquired at an angle of $45^{\circ}$ to avoid the systematic distortions which can occur with a fixed camera orientation (James and Robson 2014). The averaged GSD of the orthomosaic is finally estimated within the photogrammetric software, where the average distance from the cameras to the sparse cloud points is calculated.

For the whole flight area of $132,575 \mathrm{~m}^{2}, 28$ markers were placed on the ground at different altitudes and the relative spatial coordinates were detected through the use of two Topcon HiPer HR DGNSS receivers in Base + Rover configuration capable of horizontal accuracy of $3 \mathrm{~mm} \pm 0.1$ part per million and a vertical accuracy of $3.5 \mathrm{~mm} \pm 0.4$ part per million. This was done to ensure a high quality output model with accurate georeferencing. In total, over 1677 photos

Table 2 Summary of the parameters related to orthomosaic and DEM generated by the image processing in Metashape (Agisoft 2020)

\begin{tabular}{lllll}
\hline & Resolution & Point density & Size in pixels & Coordinate system \\
\hline Digital Elevation Model & $5 \mathrm{~cm} /$ pix & 400 points/m & $18,741 \times 12,862$ & WGS 84/UTM zone 33 N (EPSG::32,633) \\
Orthomosaic & $1.3 \mathrm{~cm} /$ pix* & N/A & $36,127 \times 34,047$ & WGS 84/UTM zone 33 N (EPSG::32,633) \\
\hline
\end{tabular}

*Averaged ground sampling distance of the orthomosaic estimated within the photogrammetric software in which the average distance from the cameras to the sparse cloud points was calculated 
were acquired during the three flights and more details are reported in Table 1.

\section{Processing}

Modern photogrammetric software packages implement the Structure from Motion (SfM) algorithms, which arise from traditional photogrammetry and have evolved thanks to the implementation of Computer Vision algorithms (Ma et al. 2012).

The theoretical principles of collinearity, intersection of projective rays and calibration of the camera, are flanked by the typical algorithms of computer vision that allow to analyse and correlate digital images in a fast and automatic way (Szeliski 2010).

There are several Structure from Motion (SfM) software packages, one of the most popular being Agisoft Metashape Professional (Agisoft 2020), which was used in this study.

The preliminary phase to image processing is the creation of the project in Agisoft Metashape and the import of photographs.

Within the same project, we created two chunks of images: the first with the images acquired at $30 \mathrm{~m}$ above the take-off point during flights 1 and 2, and the second chunk with the images acquired at a distance of about $15 \mathrm{~m}$ from the target area of the cliff face during flight 3 in manual mode.

The processing procedure includes four main steps before obtaining a complete 3D model (Fig. 3).

The first phase of processing is the alignment of the camera and serves to correctly position the images with respect to each other or, if they are already geolocated, to calculate the exact position in real space. At this stage, the software generates a sparse point cloud and it is possible to insert the GNSS coordinate on the ground control points visible in the pictures to improve the accuracy of the model. In our case, a very high accuracy was reached, with an estimated Root Mean Square Error (RMSE) at the check points of $1.14 \mathrm{~cm}$.

The second phase involves the building of a dense point cloud on the estimated camera positions.

The dense cloud of points can be modified and classified before proceeding to the generation of the 3D mesh model.

The third stage is the reconstruction of a 3D polygonal mesh representing the object surface based on the dense point cloud. After the mesh geometry is reconstructed, it is textured and used for georeferenced orthomosaic and DEM generation (Table 2).

\section{Digital geological survey method}

The progress made in the last years in the development of the UAVs and the implementation of the SfM algorithms in the new software allows us to acquire detailed multiscale information, such as the semi-automatic joint sets identification (Buyer et al. 2020; Li et al. 2019), at low cost and in a reasonable processing time. In this study, we have used open source software with plugins specially designed to quickly interpolate the structural features between the points, defined manually, in the dataset of the 3D model, orthomosaic, and DEM.

Starting from the 3D model of the Selmun promontory, to decrease the computation time during the post-processing analysis, we divided it into three smaller models. From now on, these models will be referred to as Digital Outcrop Models (DOMs).

To analyse the DOMs we used the structural geology "Compass" plugin (Thiele et al. 2017) installed in the 2.10 version (CloudComparē 2018) of the open-source software CloudCompare (Girardeau-Montaut 2015). It combines a set of flexible tools for geological interpretation that enable computerized digitization and measurement. The tools contained in the Compass plugin and used in this study are two: "Plane" and "Trace".

The Plane tool serves to measure the orientations of outcropping planar structures, such as joint surfaces. With this tool, it was possible to adapt a plane to a minimum of 3 points (with $x, y, z$ coordinates), and automatically determine the orientation of the surface. This was done using the least squares method (Fernández 2005) in which the Plane tool calculates a better fit plan through a planar regression of data that provides a medium orientation for sets of more than three points.

In the $3 \mathrm{D}$ point clouds of the Selmun promontory, we selected over 80 sets of points, corresponding to the fractures (e.g.,Sturzenegger and Stead 2009; Menegoni et al. 2019), on which a plane was constructed that gave us the surface orientations (dip/dip direction).

The Trace tool allows to digitize and measure traces and contacts. The operation of this tool is very intuitive. Selecting a start and end point along a fracture, the tool reconstructs the path, finding the trace that connects these points and reconstructing the best fit plane to estimate the orientation.

The reconstruction of the fracture path depends on the cost function used by the least-cost path algorithm (Collischonn et al. 2000). The cost function called Darkness was the most effective for the construction of tracks in our $3 \mathrm{D}$ point cloud, as they follow the dark points representing the shadows present in the fractures.

Other cost features that can be selected in this tool are lightness (the traces follow the light points in the cloud), RGB (the traces avoid colour contrasts, following points with a colour similar to the initial and final points), curvature (the tracks follow the points on ridges and valleys), gradient (traces follow colour limits such as lithological contacts), distance (the tracks follow the shortest route), scalar field 


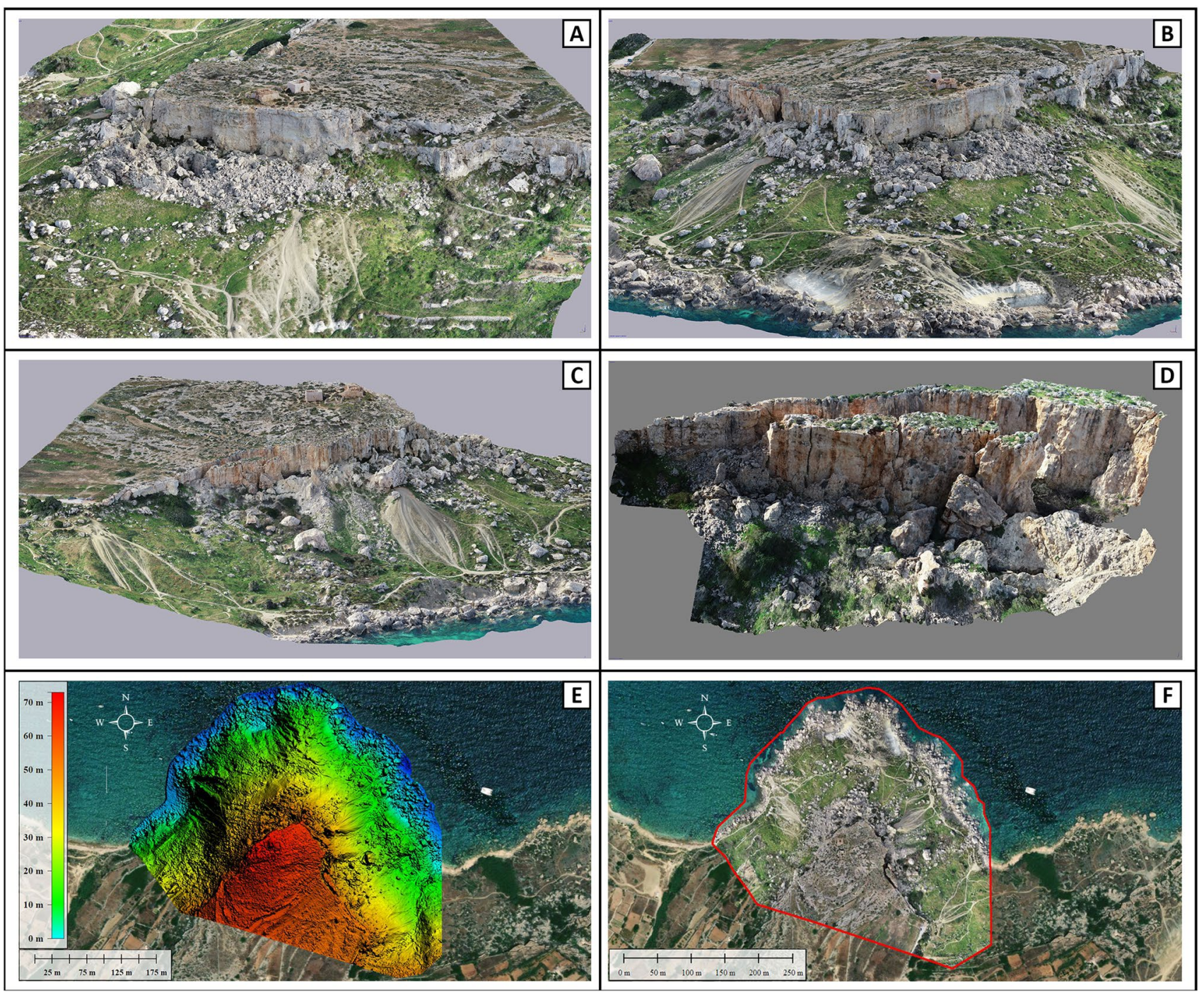

Fig. 4 Screenshots of the 3D model with exposure to North-West A, North $\mathbf{B}$, North-East $\mathbf{C}$, and detail of the east area $\mathbf{D}$ of Selmun promontory reconstructed with drone's images acquired in manual flight mode. E Digital Elevation Model and F Orthomosaic of the Selmun promontory obtained from photogrammetric process and overlapped in Google Earth Pro $^{\mathrm{TM}}$ map

(the tracks follow the low values in the active scalar field), and reverse scalar field (the traces follow high values in the active scalar field) (Thiele et al. 2017).

Another useful tool for semi-automatic fracture digitization is the GeoTrace plugin that we installed in the free and open-source geographic information system QGIS (QGIS 2015). GeoTrace allows to analyse and extract the orientations of geological structures and can be used to quickly digitize structural traces in raster data, estimate their 3D orientations using an associated DEM and then display the results on stereonets and rose diagrams (Thiele et al. 2017). The high-resolution georeferenced orthomosaic $(1.3 \mathrm{~cm} /$ pixel) obtained from the photogrammetric process was imported into QGIS and transformed into a single-channel cost raster. This operation is fundamental because the plugin uses a least-cost path algorithm to follow the linear features present in the orthomosaic. Thanks to these semi-automatic systems we were able to trace and extract all the fracture models visible both from a 3D model and from orthomosaic in much less time than we would have used with a manual operation.

\section{Results}

The Selmun case study highlights the potential of the Digital Geological Survey to provide quantitative measurements starting from a 3D model by aerial photogrammetry. The outputs obtained from the photogrammetric survey 


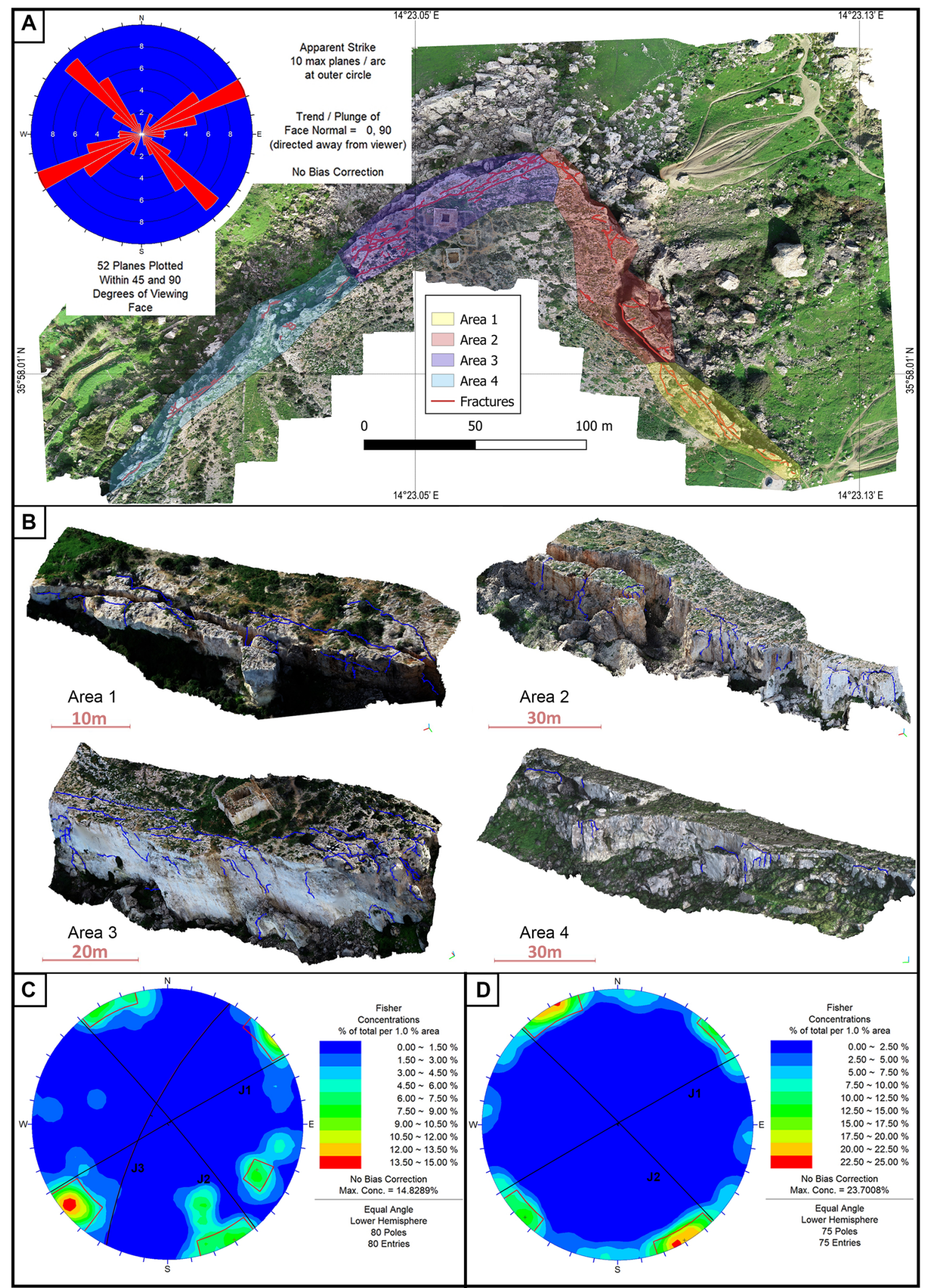

Fig. 5 A Georeferenced UAV-based orthomosaic of Selmun promontory (Malta) with semi-automatic digitized fractures map derived in a standard GIS environment. A rose diagram of joint planes (in the upper left corner) was extracted from the fractures traced in red on the orthomosaic. Areas highlighted by polygons show the positions of the four Digital Outcrop Models (DOMs). B Oblique view of DOMs constructed from aerial-photogrammetry in which fractures, highlighted in blue, have been digitized in 3D. Comparison of joint survey results on the Selmun promontory: C Stereographic projection (equalangle lower-hemisphere) of joint poles obtained by the raster and 3D model analysis and planes of the three main systems; D Stereographic projection (equal-angle lower-hemisphere) of joint poles obtained by in situ engineering-geological surveys (Iannucci et al. 2018) and planes of the two main systems 
are summarized in Fig. 4, where a three-dimensional digital model of the entire study area is shown from different viewpoints and represents the basis on which the digital geo-structural analysis took place. From the 3D model, we created a Digital Elevation Model (DEM), in which it was possible to identify the variation in altitude between 0 and $70 \mathrm{~m}$ through the scalar field with colour bar (Fig. 4E) and geo-referenced orthomosaic (Fig. 4F) in which the joints were digitalized in a semi-automatic way and plotted in terms of strikes on a rose diagram (Fig. 5A). From the 3D digital photogrammetric model, we were able to measure the thickness of the UCL, which in the area has an average value of 25-30 m. Furthermore, we estimated the overall thickness for the $\mathrm{BC}$ formation of about $50 \mathrm{~m}$. From a Digital Geological Survey, performed on the DOMs, we measured traces, contacts and orientations of joint surfaces (Fig. 5B). The results of the joint attitude at the Selmun promontory were plotted to identify the main joint systems (Fig. 5C).

The high number of measurements of the joint orientations in the DOMs provides a much more reliable description of the geometry of the fractures than the orientation at a point traditionally measured with the compass in the field. This is likely to occur because the point orientation estimates acquired with a compass are not representative of large-scale orientation. On the 3D dense cloud, we can average the orientation of the structure on large areas, and this is difficult to obtain using traditional methods. Most of the measurements made on the DOMs of the Selmun promontory are in places with reduced accessibility or even totally inaccessible. Computer-assisted digitization, able to speed up the digitization process up to $69 \%$ compared to traditional manual methods (Thiele et al. 2017), was fundamental in this study to manage the large number of measurements performed on the 3D model. Using this technique, it was also possible to measure and analyse parts of the cliff otherwise impossible to reach by an operator. The results of the joint attitude at the Selmun promontory obtained by the two different approaches [i.e., digital with orthomosaic and DOMs analysis (Fig. 5C), and manual with in-situ engineering-geological surveys (Fig. 5D)], were plotted separately so that any differences in the identified main joint systems could be observed. As already noted by Iannucci et al. (2018), the stereographic projection (equal-angle lower-hemisphere) of the joint poles surveyed by in-situ engineering-geological investigations defines two main systems of sub-vertical joints at the Selmun promontory (Fig. 5D): J1 with a mean dip direction of $330^{\circ}$ (strike $60^{\circ}$ or $240^{\circ}$ ) and mean dip of $89^{\circ}$, prevalent in the $\mathrm{NW}$ zone, and $\mathrm{J} 2$ with mean dip direction $45^{\circ}$ (strike $135^{\circ}$ or $315^{\circ}$ ) and mean dip of $88^{\circ}$, prevalent in the SE zone. A similar result can be observed by studying the stereographic projection of the joint poles identified by the raster and DOMs analysis (Fig. 5C). This analysis confirmed the presence of the two above-mentioned main systems of sub-vertical joints: $\mathrm{J} 1$ having mean dip direction of $330^{\circ}$ (strike of $60^{\circ}$ or $240^{\circ}$ ) with mean dip of $89^{\circ}$ and $\mathrm{J} 2$ having mean dip direction of $50^{\circ}$ (strike $140^{\circ}$ or $320^{\circ}$ ) and mean dip of $86^{\circ}$. The difference of $5^{\circ}$ in the dip direction of $\mathrm{J} 2$ is not significant and could be attributed to the different datasets of joints analysed. In addition, a third joint system resulted from studying the pole distribution: J3, with a mean dip direction of $297^{\circ}$ (strike $27^{\circ}$ or $207^{\circ}$ ) and a mean dip of $73^{\circ}$, therefore not sub-vertical as the other two joint systems. The failure to detect this joint system by the in situ engineering-geological surveys could be explained by the inability to investigate the UCL cliff walls, which was only possible through analysis of the UAV-photogrammetric model. The diagram obtained by the plotting of DOMs measurement (Fig. 5C) confirmed the results of the in situ engineeringgeological surveys. We observe the presence of two main joint systems on the Selmun promontory: a first system (31\% of frequency) having a strike of $50^{\circ}-70^{\circ}$ (or $230^{\circ}-250^{\circ}$ ), that have an attitude similar to the previously defined system $\mathrm{J} 1$, and a second system ( $29 \%$ of frequency) with a strike of $130^{\circ}-150^{\circ}$ (or $310^{\circ}-330^{\circ}$ ), that can be referred to the system $\mathrm{J} 2$.

Using the 3D model it was also possible to obtain detailed estimates of the block dimensions (e.g., Liu et al. 2017). The blocks were manually selected from the 3D model and their volume was calculated (Fig. 6), assuming a UCL density ( $\rho$ ) value of $2146 \mathrm{~kg} \mathrm{~m}^{-3}$ (Iannucci et al. 2018). Thus, it was possible to estimate the jointed rock masses involved in the erosion processes.

In addition, each block was mapped in the orthomosaic and these data were reported in a GIS database that will be used as a basis for monitoring the movement of volumes over time. Through periodic photogrammetric surveys, it is also possible to detect automatically the estimated volumetric flux of falling rocks (Gilham et al. 2019). Finally, as a further output, a high-resolution geomorphological map (Fig. 7) was created, starting from DEM and orthomosaic generated by aerial photogrammetry. This map illustrates the geology of the study area and contains a digital repository of main geomorphological features such as the main fractures and boulders.

\section{Discussion and conclusion}

In this study, we used UAV-Photogrammetry to reconstruct in three dimensions the landscape of the Selmun promontory (north-eastern coast of Malta).

This is the first such application for the Maltese Islands and we show that the digital survey approach opens up 


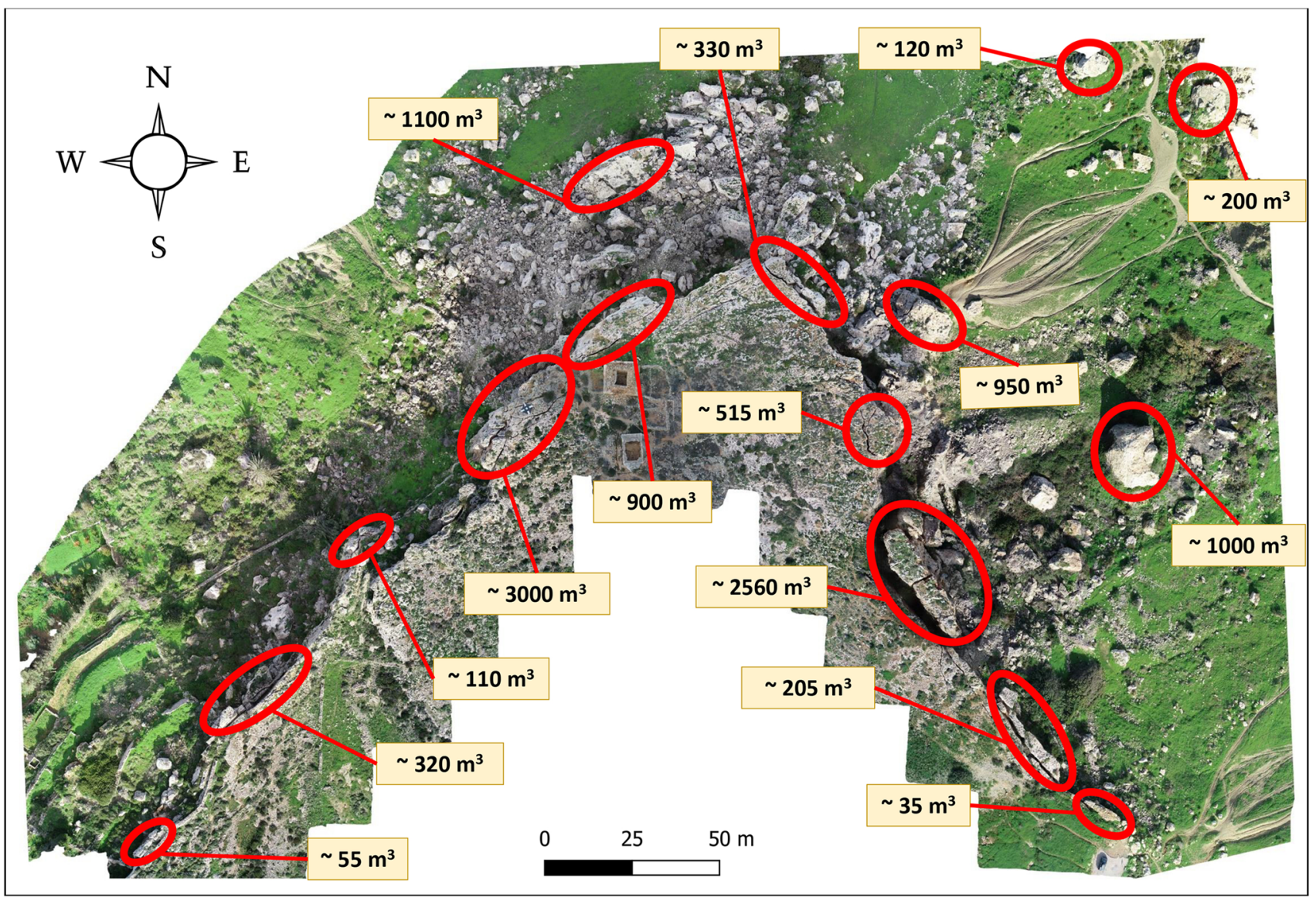

Fig. 6 Orthomosaic of the Selmun promontory with the volumes of some blocks measured in the 3D model

new possibilities for analysing and interpreting geological data by providing a stereoscopic view that allows the user to visualize and map the study area remotely and from perspectives that are very difficult to obtain in the field.

This enabled us to perform a digital geological survey in which we identified the main joint systems and measured traces, contacts and orientations of joint surfaces. One of the objectives of the Digital Geological Survey in this area was to verify the potential of this method by comparing these results with those obtained in previous studies (Iannucci et al. 2017, 2018).

The effectiveness of this methodology, in comparison with conventional in situ geological surveying, has been proved during this study as a new joint system $(\mathrm{J} 3)$ was identified from the measurements taken on the 3D model of the Selmun cliffs (Fig. 5C). Thanks to the additional perspective it was possible to improve the results of manual measurements by being able to measure fractures present in areas inaccessible to a person.

A summary of the main results of this study and relative comparison with traditional geological survey data are given in Table 3 . In the case of $\mathbf{J} 2$, the range of the opening of the joint systems measured in the field differ from those measured by the 3D model (see Table 3). This is due to the fact that in this study we were able to map a portion of the cliff that was not possible to investigate by means of traditional geological mapping techniques since it was unsafe and/or impossible for an operator to access some partially detached areas from the cliff and make measurements.

Furthermore, a detailed volume analysis of blocks and debris was done (Fig. 6) using the 3D model while a detailed geomorphological map was drawn (Fig. 7) from the orthomosaic and DEM.

Currently, there is no geomorphological map on a national scale and just one attempt has been made on the north-western coast of Malta (Devoto et al. 2012). In our study, a geomorphological map (scale 1:1000) has been produced and particular emphasis was placed on the identification and mapping of jointed and fractured areas as well as the mapping of debris and blocks, which may involve dangerous situations for residents and tourists. Due to its high detail, it constitutes a reliable basic document, which could be useful for the Maltese authorities for the identification of areas exposed to geographical 


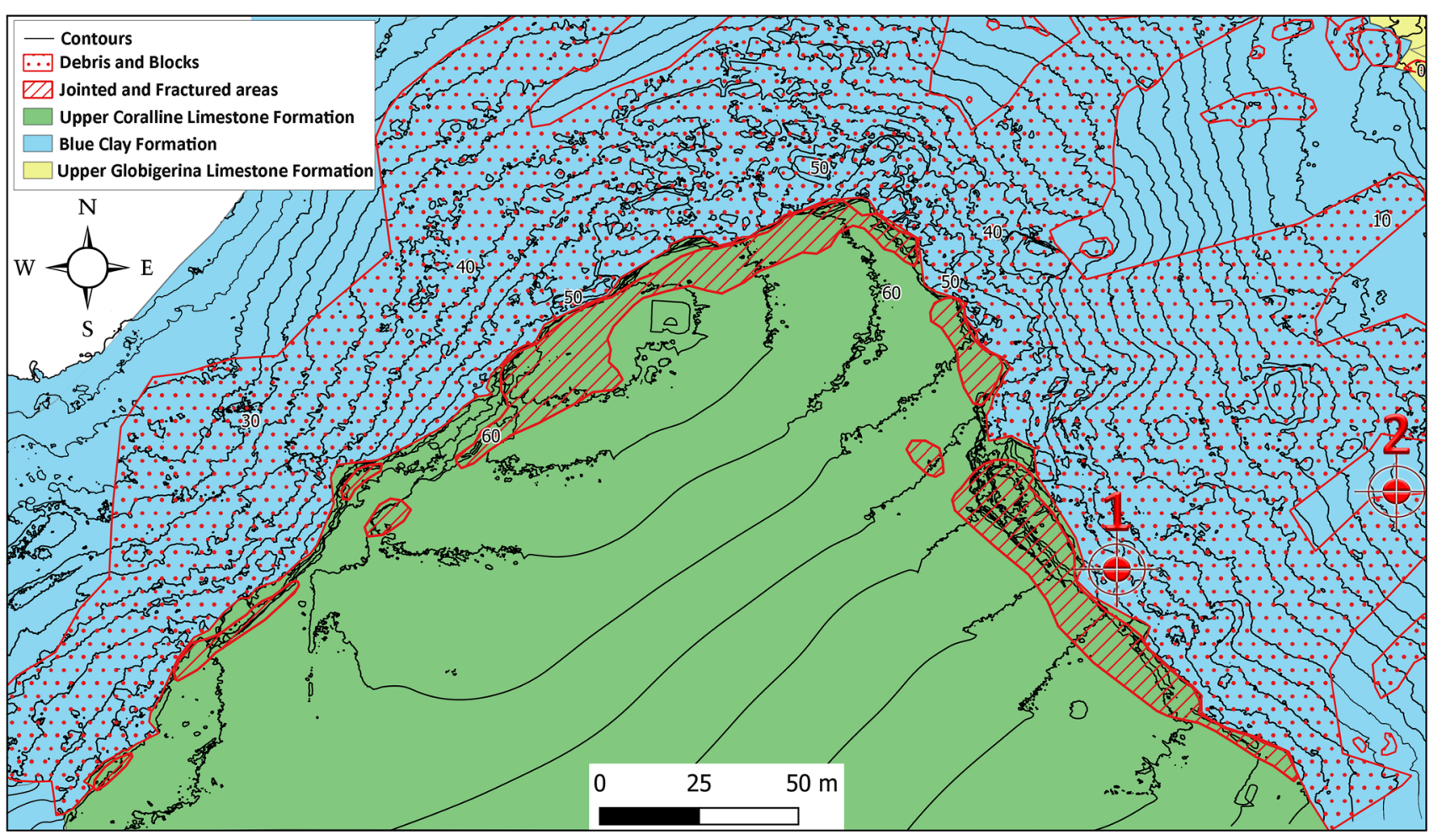

Fig. 7 Geomorphological map of the Selmun Area (Malta) in GIS platform (scale 1:2500) and the two points where ambient noise was recorded (red dots 1 and 2)

Table 3 Summary of the properties of the rock mass joints derived from the manual geological survey by Iannucci et al. 2018 and the digital geological survey (this study)

\begin{tabular}{|c|c|c|c|c|}
\hline \multirow[t]{2}{*}{$\begin{array}{l}\text { Joints pole sys- } \\
\text { tems }\end{array}$} & \multicolumn{2}{|c|}{$\begin{array}{l}\text { Manual geological survey (Iannucci et al. } \\
\text { 2018) }\end{array}$} & \multicolumn{2}{|c|}{ Digital geological survey (This study) } \\
\hline & $\begin{array}{l}\text { Dip direction and } \\
\operatorname{dip}\left(^{\circ}\right)\end{array}$ & $\begin{array}{l}\text { Range of joint opening } \\
\text { in } \mathrm{cm}\end{array}$ & $\begin{array}{l}\text { Dip direction and } \\
\operatorname{dip}\left(^{\circ}\right)\end{array}$ & $\begin{array}{l}\text { Range of joint } \\
\text { opening in } \mathrm{cm}\end{array}$ \\
\hline $\mathrm{J} 1$ & $330 / 89$ & $1-105$ & $330 / 89$ & $1-100$ \\
\hline $\mathrm{J} 2$ & $45 / 88$ & $1-70$ & $050 / 86$ & $1-320$ \\
\hline $\mathrm{J} 3$ & N/A & N/A & $297 / 73$ & $1-30$ \\
\hline
\end{tabular}

hazards and future planning. The DEM generated in this study has a density of 400 points $/ \mathrm{m}^{2}$, which compared to the LiDAR-derived DEM with 4.3 points $/ \mathrm{m}^{2}$ (ERDF 156 Data 2013) is almost a hundred times denser, and therefore allows identification of areas exposed to landslides as well as better recognition of geological features. The proposed approach will contribute also to the management of the area as a whole and it can be extended to the mapping of other "features" (e.g., vegetation cover, evolution of coastline) and data can be used "holistically" for further recognition, assessment and planning of geomorphosites (e.g., Reynard et al. 2009; Coratza et al. 2011).

Using the DEM and the geomorphological map, it was possible to measure the height difference in altitude of two points (as an example, we considered Points 1 and 2 in Fig. 7). This difference resulted in about $25 \mathrm{~m}$. At the same two locations, we measured the thicknesses of the $\mathrm{BC}$ by inverting the Horizontal-to-Vertical Spectral Ratio (HVSR) of ambient seismic noise. Seismic noise measurements were taken by means of a portable seismometer. The HVSR curves are characterized by peaks generally associated with the interface separating the BC layer from the GL. When performed on top of partly detached blocks of the cliff face, these curves also show peaks at a higher frequency related to the vibrations of the detached blocks from the cliff. (e.g.,Pino et al. 2018; Pischiutta et al 2016; Scolaro et al. 2018; Villani et al.2018 and reference therein). Iannucci et al. (2018) carried out an extensive ambient noise survey to characterize the complex landslide system in the area. In particular, more than a hundred single-station noise measurements were carried out to cover the inland area and the edge of the limestone plateau as well as the slope where the clays outcrop. 
To estimate the thickness of the BC, we carried out 1-D modelling, computing synthetic HVSR curves using Grilla ${ }^{\circledR}$ software (further details on the procedure and values of rock densities and shear wave velocities used to constrain the inversion are given in Panzera et al. 2012, 2013; Vella 2013; Farrugia et al. 2016, 2017; Iannucci et al. 2018, 2020). We estimated a difference in BC thickness of about 22-25 m between points 1 and 2 , which is consistent with the measurement on the DEM.

In conclusion, aerial photogrammetry ensures the safety of the operator in the field, especially in difficult or hostile geological environments that could pose a risk to human life, such as cliff areas, unstable slopes, offshore islands, volcanoes, etc. (e.g., Panzera et al. 2018). The measured dimensions of the blocks, extracted from the 3D model in this study, could eventually also be used to obtain the eigenmode frequencies of the individual blocks using numerical modelling and encourage studies that compare theoretical and observed vibration of the detached or nearly detached boulders with the aim of simulating and/or monitoring rock failure, collapse, as well as rockfall analysis (e.g.,Guinau et al. 2019; Iannucci et al. 2020). Monitoring of unstable cliff areas could provide an important contribution to hazard and risk assessment, and a vital tool for coastal zone management and civil protection. The great advantage of the approach presented in this study is given by the possibility of tracing and extracting all visible fracture patterns and making position measurements in much less time than would be required with manual operation. Moreover, the georeferenced orthomosaic can be exported in $\mathrm{KMZ}$ format for Google Earth Pro ${ }^{\mathrm{TM}}$ to facilitate visualization to policymakers and stakeholders who are not familiar with GIS software. All data collected during this study are published as open access data, on the public repositories of high-resolution topographic data OpenTopography (Crosby et al. 2013).

\begin{abstract}
Acknowledgements This research is part of the $\mathrm{Ph} . \mathrm{D}$. research project of Emanuele Colica at University of Malta. This study was partially supported by the project "NEWS-Nearshore hazard monitoring and Early Warning System" (code C1-3.2-60) part-financed by the European Union under the Italia-Malta Cross-Border Cooperation Programmes, 2014-2020. The authors are grateful to Prof. Louis Cassar (Institute of Earth Systems, University of Malta) for his help during field activities, data acquisition and useful discussion that contributed to improve the final version of the manuscript.
\end{abstract}

Funding This study was partially supported by the project NEWS ("Nearshore hazard monitoring and Early Warning System") partfinanced by the European Union under the Italia- Malta Cross-Border Cooperation Programmes, 2014-2020.

Availability of data and material Data are available upon request.

Code availability No software applications or custom code have been developed.

\section{Declarations}

Conflict of interest The authors declare that they have no known competing financial interests or personal relationships that could have appeared to influence the work reported in this paper.

Open Access This article is licensed under a Creative Commons Attribution 4.0 International License, which permits use, sharing, adaptation, distribution and reproduction in any medium or format, as long as you give appropriate credit to the original author(s) and the source, provide a link to the Creative Commons licence, and indicate if changes were made. The images or other third party material in this article are included in the article's Creative Commons licence, unless indicated otherwise in a credit line to the material. If material is not included in the article's Creative Commons licence and your intended use is not permitted by statutory regulation or exceeds the permitted use, you will need to obtain permission directly from the copyright holder. To view a copy of this licence, visit http://creativecommons.org/licenses/by/4.0/.

\section{References}

Agisoft LLC (2020) Metashape user manual, professional edition, version 1.7. URL. https://www.agisoft.com/pdf/metashapepro_1_7_en.pdf. Accessed 20 Dec 2020

Agisoft LLC, St Petersburg R (2020) Agisoft metashape professional edition

Buyer A, Aichinger S, Schubert W (2020) Applying photogrammetry and semi-automated joint mapping for rock mass characterization. Eng Geol 264:105332

Casella E, Collin A, Harris D, Ferse S, Bejarano S, Parravicini V, Rovere A (2017) Mapping coral reefs using consumer-grade drones and structure from motion photogrammetry techniques. Coral Reefs 36(1):269-275

Chandler J (1999) Effective application of automated digital photogrammetry for geomorphological research. Earth Surf Process Landf 24(1):51-63

CloudCompare (versioñ 2.10) [GPL software] (2018) Retrieved from: http://www.cloudcompare.org/. Accessed 20 Dec 2020

Colica E, Micallef A, D’Amico S, Cassar LF, Galdies C, Restall B, Furlani S (2017) Investigating the use of UAV systems for photogrammetric applications: a case study of Ramla Bay (Gozo, Malta). XJENZA 2017:04

Collischonn W, Pilar JV (2000) A direction dependent least-cost-path algorithm for roads and canals. Int J Geogr Inf Sci 14(4):397-406

Coratza P, Bruschi VM, Piacentini D, Saliba D, Soldati M (2011) Recognition and assessment of geomorphosites in Malta at the Il-Majjistral nature and history park. Geoheritage 3:175-185

Crosby C, Nandigam V, Baru C, Arrowsmith JR (2013) Opentopography: enabling online access to high-resolution lidar topography data and processing tools. In: EGU general assembly conference abstracts (p 13326)

D’Amico S, Saccone M, Persico R, Venuti V, Spagnolo G, Crupi V, Majolino D (2017) 3D survey and GPR for cultural heritage. The case study of SS. Pietro and Paolo Church in Casalvecchio Siculo. Kermes 107:11-15

Devoto S, Biolchi S, Bruschi VM, Furlani S, Mantovani M, Piacentini D, Soldati M (2012) Geomorphological map of the NW coast of the island of Malta (Mediterranean Sea). J Maps 8(1):33-40

Devoto S, Biolchi S, Bruschi VM, Díez AG, Mantovani M, Pasuto A, Soldati M (2013) Landslides along the north-west coast of the 
Island of Malta. In: Margottini C, Canuti P, Sassa K (eds) Landslide science and practice. Springer, Berlin

El Gamal A, Eltoukhy H (2005) CMOS image sensors. IEEE Circuits Devices Mag 21(3):6-20

ERDF 156 Data (2013) Developing national environmental monitoring infrastructure and capacity. Malta Environment \& Planning Authority, Malta

Farrugia F, Paolucci E, D’Amico S, Galea P (2016) Inversion of surface-wave data for subsurface shear-wave velocity profiles characterised by a thick buried low-velocity layer. Geophys J Int 206:1221-1231. https://doi.org/10.1093/gji/ggw204

Farrugia D, Galea P, D’Amico S, Paolucci E (2017) Sensitivity of ground motion parameters to local shear-wave velocity models: the case of buried low-velocity layers. Soil Dyn Earthq Eng 100:196-205. https://doi.org/10.1016/j.soildyn.2017.05.033

Fazio NL, Perrotti M, Andriani GF, Mancini F, Rossi P, Castagnetti C, Lollino P (2019) A new methodological approach to assess the stability of discontinuous rocky cliffs using in-situ surveys supported by UAV-based techniques and 3-D finite element model: a case study. Eng Geol 260:105205

Fernández O (2005) Obtaining a best fitting plane through 3D georeferenced data. J Struct Geol 27(5):855-858

Fonstad MA, Dietrich JT, Courville BC, Jensen JL, Carbonneau PE (2013) Topographic structure from motion: a new development in photogrammetric measurement. Earth Surf Process Landf 38(4):421-430

Francioni M, Salvini R, Stead D, Litrico S (2014) A case study integrating remote sensing and distinct element analysis to quarry slope stability assessment in the Monte Altissimo area, Italy. Eng Geol 183:290-302

Galea P, D'Amico S, Farrugia D (2014) Dynamic characteristics of an active coastal spreading area using ambient noise measurements (Anchor Bay, Malta). Geophys J Int 199:1166-1175. https://doi. org/10.1093/gji/ggu318

Galea P, Bozionelos G, D’Amico S, Drago A, Colica E (2018) Seismic signature of the azure window collapse, Gozo, Central Mediterranean. Seismol Res Lett 89(3):1108-1117. https://doi.org/10. $1785 / 0220170115$

Gauci R, Scerri S (2019) A synthesis of different geomorphological landscapes on the Maltese Islands. In: Gauci R, Schembri JA (eds) Landscapes and landforms of the Maltese Islands. Springer, Cham, pp 49-65

Gilham J, Barlow J, Moore R (2019) Detection and analysis of mass wasting events in chalk sea cliffs using UAV photogrammetry. Eng Geol 250:101-112

Girardeau-Montaut D (2015) Cloud compare-3d point cloud and mesh processing software. Open Source Project

Gonçalves JA, Henriques R (2015) UAV photogrammetry for topographic monitoring of coastal areas. ISPRS J Photogramm Remote Sens 104:101-111

Goudie A (2004) Encyclopedia of geomorphology. Routledge

Grosse P, van de Vries WB, Euillades PA, Kervyn M, Petrinovic IA (2012) Systematic morphometric characterization of volcanic edifices using digital elevation models. Geomorphology 136(1):114-131

Guinau M, Tapia M, Pérez-Guillén C, Suriñach E, Roig P, Khazaradze G, Echeverria A (2019) Remote sensing and seismic data integration for the characterization of a rock slide and an artificially triggered rock fall. Eng Geol 257:105113

Heng BCP, Chandler JH, Armstrong A (2010) Applying close range digital photogrammetry in soil erosion studies. Photogramm Record 25(131):240-265

Hutchinson JN (1988) General report: morphological and geotechnical parameters of landslides in relation to geology and hydrogeology. In: proceedings of fifth international symposium on landslides, vol 1, p 3-35
Hyde HPT (1955) Geology of the Maltese Islands. Lux Press, Montreal Iannucci R, Martino S, Paciello A, D’Amico S (2017) Rock mass characterization coupled with seismic noise measurements to analyze the unstable cliff slope of the Selmun promontory (Malta). Proced Eng 191:263-269

Iannucci R, Martino S, Paciello A, D'Amico S, Galea P (2018) Engineering geological zonation of a complex landslide system through seismic ambient noise measurements at the Selmun promontory (Malta). Geophys J Int 213(2):1146-1161. https://doi.org/ 10.1093/gji/ggy025

Iannucci R, Martino S, Paciello A, Amico S, Galea P (2020) Investigation of cliff instability at Ghajn Hadid Tower (Selmun promontory, Malta) by integrated passive seismic techniques. J Seismol. https://doi.org/10.1007/s10950-019-09898-z

ISRM (1978) Suggested methods for the quantitative description of discontinuities in rock masses. Int J Rock Mech Min Sci Geomech Abstr 15:319-368

James MR, Robson S (2014) Mitigating systematic error in topographic models derived from UAV and ground-based image networks. Earth Surf Proc Land 39(10):1413-1420

Lane SN (2000) The measurement of river channel morphology using digital photogrammetry. Photogramm Rec 16(96):937-961

Laribi A, Walstra J, Ougrine M, Seridi A, Dechemi N (2015) Use of digital photogrammetry for the study of unstable slopes in urban areas: case study of the El Biar landslide, Algiers. Eng Geol 187:73-83

Leachtenauer JC, Driggers RG (2001) Surveillance and reconnaissance imaging systems: modeling and performance prediction. Artech House

Li R, Di K, Ma R (2003) 3-D shoreline extraction from IKONOS satellite imagery. Mar Geodesy 26(1-2):107-115

Li X, Chen Z, Chen J, Zhu H (2019) Automatic characterization of rock mass discontinuities using 3D point clouds. Eng Geol 259:105131

Liu T, Deng J, Zheng J, Zheng L, Zhang Z, Zheng H (2017) A new semi-deterministic block theory method with digital photogrammetry for stability analysis of a high rock slope in China. Eng Geol 216:76-89

Ma Y, Soatto S, Kosecka J, Sastry SS (2012) An invitation to 3-d vision: from images to geometric models, vol 26. Springer, Berlin

Mantovani M, Devoto S, Forte E, Mocnik A, Pasuto A, Piacentini D, Soldati M (2013) A multidisciplinary approach for rock spreading and block sliding investigation in the north-western coast of Malta. Landslides 10(5):611-622

Martino S, Mazzanti P (2014) Integrating geomechanical surveys and remote sensing for sea cliff slope stability analysis: the Mt. Pucci case study (Italy). Nat Hazards Earth Syst Sci 14(4):831-848

Menegoni N, Giordan D, Perotti C, Tannant DD (2019) Detection and geometric characterization of rock mass discontinuities using a 3D high-resolution digital outcrop model generated from RPAS imagery-Ormea rock slope, Italy. Eng Geol 252:145-163

Oil Exploration Directorate (1993) Office of the Prime Minister, Geological Map of the Maltese Islands, Valletta, Malta

Panzera F, D'Amico S, Lotteri A, Galea P, Lombardo G (2012) Seismic site response of unstable steep slope using noise measurements: the case study of Xemxija Bay area, Malta. Nat Hazards Earth Syst Sci 12(11):3421-3431

Panzera F, D'Amico S, Galea P, Lombardo G, Gallipoli R, Pace S (2013) Geophysical measurements for site response investigation: preliminary results on the island of Malta. Boll Geo Teo Appl. https://doi.org/10.4430/bgta0084

Panzera F, D’Amico S, Lupi M, Mauri G, Karyono K, Mazzini A (2018) Lusi hydrothermal structure inferred through ambient vibration measurements. Mar Pet Geol 90:116-124

Pedley M (2011) The Calabrian stage, pleistocene highstand in Malta: a new marker for unravelling the late neogene and quaternary history of the islands. J Geol Soc 168(4):913-926 
Pedley HM, House MR, Waugh B (1976) The geology of Malta and Gozo. Proc Geol Assoc 87(3):325-341

Pedley HM, House MR, Waugh B (1978) The geology of the Pelagian block: the Maltese islands. In: Nairn AEM, Kanes WH, Stehli FG (eds) The ocean basins and margins. Plenum Press, New York, pp 417-433

Pino P, D'Amico S, Orecchio B, Presti D, Scolaro S, Torre A, Neri G (2018) Integration of geological and geophysical data for re evaluation of local seismic hazard and geological structure: the case study of Rometta, Sicily (Italy). Ann Geophy 61(2):SE227

Pischiutta M, Villani F, D’Amico S, Vassallo M, Cara F, Di Naccio D, Farrugia D, Di Giulio G, Amoroso S, Cantore P, Mercuri A, Famiani D, Galea P, Akinci A, Rovelli A (2016) Results from shallow geophysical investigations in the northwestern sector of the island of Malta. Phys Chem Earth. https://doi.org/10.1016/j. pce.2016.10.013

Pix4Dcapture (2018). Retrieved from: https://www.pix4d.com/produ ct/pix4dcapture

QGIS A (2015) Free and open source geographic information system. Open source geospatial foundation project

Remondino F, Barazzetti L, Nex F, Scaioni M, Sarazzi D (2011) UAV photogrammetry for mapping and $3 \mathrm{~d}$ modeling-current status and future perspectives. Int Arch Photogramm Remote Sens Spatial Inf Sci 38(1):C22

Reynard E, Coratza P, Regolini-Bissig G (2009) Geomorphosites. Verlag Dr Friedrich Pfeil, Mnichov, pp 63-73

Scerri S (2019) Sedimentary evolution and resultant geological landscapes. In: Gauci R, Schembri JA (eds) Landscapes and landforms of the Maltese Islands. Springer, Cham, pp 31-47

Scolaro S, Pino P, D’Amico S, Orecchio B, Presti D, Torre A, Totaro C, Farrugia D, Neri G (2018) Ambient noise measurements for preliminary microzoning studies in the city of Messina, Sicily. Ann Geophys. https://doi.org/10.4401/ag-7711

Sturzenegger M, Stead D (2009) Close-range terrestrial digital photogrammetry and terrestrial laser scanning for discontinuity characterization on rock cuts. Eng Geol 106(3-4):163-182
Szeliski R (2010) Computer vision: algorithms and applications. Springer, Berlin

Thiele ST, Grose L, Samsu A, Micklethwaite S, Vollgger SA, Cruden AR (2017) Rapid, semi-automatic fracture and contact mapping for point clouds, images and geophysical data. Solid Earth Discuss. https://doi.org/10.5194/se-8-1241-2017

Varnes DJ (1978) Slope movement types and processes. In: Schuster RL, Krizek RJ (eds) Landslides analysis and control, special report 176. National Academy of Science, Washington, DC, pp $11-33$

Vella A, Galea P, D’Amico S (2013) Site response characterisation of the Maltese islands based on ambient noise HVSR. Eng Geol 163:89-100. https://doi.org/10.1016/j.enggeo.2013.06.006

Villani F, D’Amico S, Panzera F, Vassallo M, Bozionelos G, Farrugia D, Galea P (2018) Shallow high-resolution geophysical investigation along the western segment of the Victoria Lines Fault (island of Malta). Tectonophysics 724-725:220-233. https://doi.org/10. 1016/j.tecto.2018.01.010

Wenzel K, Rothermel M, Fritsch D, Haala N (2013) Image acquisition and model selection for multi-view stereo. Int Arch Photogramm Remote Sens Spatial Inf Sci 40:251-258

Westoby MJ, Brasington J, Glasser NF, Hambrey MJ, Reynolds JM (2012) 'Structure-from-Motion' photogrammetry: a low-cost, effective tool for geoscience applications. Geomorphology 179:300-314

Wu JH, Lin WK, Hu HT (2018) Post-failure simulations of a large slope failure using 3DEC: the Hsien-du-shan slope. Eng Geol 242:92-107

Publisher's Note Springer Nature remains neutral with regard to jurisdictional claims in published maps and institutional affiliations. 